\title{
Archaeometallurgical Analyses on Two Renaissance Swords from the "Luigi Marzoli" Museum in Brescia: Manufacturing and Provenance
}

\author{
Carolina Mori ${ }^{1}$, Giorgia Ghiara ${ }^{2}{ }^{*} \mathbb{D}$, Paolo De Montis ${ }^{3}$, Paolo Piccardo ${ }^{2} \mathbb{D}$, Giacomo D. Gatta ${ }^{4}$ \\ and Stefano Pierpaolo Trasatti ${ }^{1}$ (D) \\ 1 Department of Environmental Sciences and Policy (ESP), Università degli Studi di Milano, \\ 20133 Milano, Italy; moricarolina@live.it (C.M.); stefano.trasatti@unimi.it (S.P.T.) \\ 2 Department of Chemistry and Industrial Chemistry (DCCI), Università degli Studi di Genova, \\ 16146 Genova, Italy; paolo.piccardo@unige.it \\ 3 Accademia di San Marciano, 10143 Torino, Italy; paolo.demontis89@gmail.com \\ 4 Department of Earth Sciences, Università degli Studi di Milano, 20133 Milano, Italy; diego.gatta@unimi.it \\ * Correspondence: giorgia.ghiara@gmail.com
}

check for

updates

Citation: Mori, C.; Ghiara, G.; De Montis, P.; Piccardo, P.; Gatta, G.D.; Trasatti, S.P. Archaeometallurgical Analyses on Two Renaissance Swords from the "Luigi Marzoli" Museum in Brescia: Manufacturing and Provenance. Heritage 2021, 4 , 1269-1283. https://doi.org/10.3390/ heritage 4030069

Academic Editor: Chiara Soffritti

Received: 22 June 2021

Accepted: 12 July 2021

Published: 14 July 2021

Publisher's Note: MDPI stays neutral with regard to jurisdictional claims in published maps and institutional affiliations.

Copyright: (C) 2021 by the authors Licensee MDPI, Basel, Switzerland. This article is an open access article distributed under the terms and conditions of the Creative Commons Attribution (CC BY) license (https:/ / creativecommons.org/licenses/by/ $4.0 /)$.

\begin{abstract}
Two Venetian types of swords coming from the "Luigi Marzoli" Arms Museum in Brescia were characterized in this study, to understand their manufacturing process and to gather information about their provenance. Both the blades and the hilts components are analyzed using a multimethodological approach, to describe possible differences in the metallurgical features that involved classical metallographic and spectroscopic techniques. Microstructural results indicate a complex process for the manufacturing of the blades, by hot-forging, confirmed by a sequence of different microstructures even on the same sample. Furthermore, an interesting and unusual manufacturing technique is used on one of the pommels, which consists of two hemispheres connected by copper joints. Hypothesis about the ironmaking and the provenience of raw materials are obtained by the features and composition of the inclusions. It is suggested that there is the use of both a direct and an indirect process on the swords. It is likely that the minerals used to obtain iron and copper of the swords come from the mines of the Brescia and Bergamo territories. All the hypotheses are consistent with the historical documents of the time that also give information on the diffusion of such swords in the Brescia area.
\end{abstract}

Keywords: Venetian type swords; metallography; copper joints; inclusions; EPMA-WDS

\section{Introduction}

The study of ancient iron swords is of common interest for the cultural heritage context as it delivers information on the specific metallurgical knowledge of ancient times. Many studies have been performed to find out the metallurgical characteristics of ancient weaponry, most of them using a classical invasive protocol that involves the sampling of representative parts of the object and metallurgical instrumentation to identify its exact manufacturing process [1-4]. Through microstructural analysis, much information about the forging processes and the thermal treatments can be extracted [5-9]. However, recently the need for a non-invasive kind of techniques has led the researcher's attention to some studies that consider new analytical protocols. Nondestructive methods were carried out on swords coming from different time periods (from the iron age to the renaissance) to obtain chemical analyses [10-12] and combined with X-ray radiograph to observe inscriptions and traces of welding at the joint of the hilt and the blade [5]. In addition, many studies addressed the issue of ironmaking throughout history with neutron diffraction techniques, by the analysis of the microstructural features obtained through the diffraction patterns [13-16]. However, these techniques are very complex and require very sophisticated instrumentation that cannot be affordable to anyone. To obtain reliable information 
on both the manufacturing process and the provenance, classical metallographic techniques are still the best choice in terms of cost-effectiveness. In addition, electron microanalyses are associated with metallurgical studies to understand the type of ironmaking process [7,17]. To our knowledge, most of the data from the literature on ancient swords were on the blades, with very few studies carried out on the other components of the swords [18,19]. In particular, the study of renaissance swords was performed mainly by Williams et. al., who carried out intensive research on the evolution of both the blacksmith metallurgical practices and the extraction techniques throughout the centuries [20,21].

In this study, we aim to provide more detailed information on the metallurgy of the classical Venetian type of swords, largely widespread since the 15th century in the entire Europe. Two swords coming from "Luigi Marzoli" Arms Museum in Brescia, the most distinguished area of sword making since the 15th century, were analyzed using classical metallographic techniques and allowed us to provide new insights on peculiar assembling procedures and extraction techniques that could correlate the raw materials to the possible local iron ores.

\section{Historical Context}

The 15th century can be defined as a century of great importance for the development of metallurgy and, accordingly, of arms production in Italy, without considering the rest of Europe. It was the crux of the translation in many scopes tied to the weapons' world: from the direct to the indirect method of reducing iron, in the strategy and the forging processes. Therefore, these objects are evidence of these changes in metallurgy between the Late Middle Ages and the Modern Ages. One of the key elements of this development was the affirmation of the indirect method for iron production, thanks to the development of furnaces called "a canecchio" [22,23]. These ovens, also called "alla bresciana" (Brescia type) or "alla bergamasca" (Bergamo type), took their name from the tower in square stones, sealed with mortar, in which the iron ore was reduced by burning coal. In these ovens, metal was kept (due to the introduction of long walls, to the use of bellows and, later, hydro-wind horns) at very high temperatures that brought it in contact with the carbon monoxide for long periods of time, generating cast iron. This alloy bears a high carbon content and has difficult workability. Accordingly, it was transformed into iron using "large fires" (furnaces with large central cavities where the metal was fired and later subjected to decarburization). The spread of these units, able to provide iron of a much higher quality than that obtained with the direct method, was one of the reasons behind the development of the great arms centers in northern Italy, such as Brescia, Milan, Belluno, Feltre, Serravalle and Gromo in the Bergamo area [24]. In the Venetian territory, the Bergamo area and the Brescia area assumed great importance as sword production centers, so that the Venetian chancellors had reported an important number of furnaces and forgings in the middle of the 15th century $[25,26]$. Likely, workers from Brescia and Bergamo emigrated to contribute to the affirmation of the Val di Zoldo, in the Belluno area, as a leading iron center from the 15th century. Although probably the indirect method was already practiced there in the 14th century [27], it is important to remember that the furnaces "a canecchio" and blast furnaces have coexisted with the ancient blooming furnaces up to the 19th century in Italy [28]. In the same period, while Serravalle and Ceneda in the Treviso area, Gromo in the Bergamo area, and the Brescia area began to play an important role as sword production centers [29,30], the production of swords in the Belluno area dates to the early years of the 15th century [31]. The most important ores used by the Venetians were in Val Trompia, in the Brescia area [32], and Fursil mine [31], presently in the Belluno area, but at that time under the Bressanone princes-bishops domination. The main iron-bearing mineral, extracted in all the principal mines of the territory, was siderite, as a component of (often metasomatic) carbonate rocks. With time, the affirmation of these production districts led to a substantial transformation of the sword object, aimed at improving the grip and making the hilt more ergonomic, the beginnings of which can be seen since the 13th century [24]. In the Spanish and Italian area, branches were introduced, rings placed on the two edges 
of the blade, which housed the index and middle fingers of the hand, while the palm was placed on the grip. Another element added was the knuckle-guard, a curved branch that departing from the center of the quillon reached the pommel; it also guaranteed greater protection to the swordsman's hand. According to the documents of the fifteenth century, the components that changed the most were the hilts: the blades, generally wide and not particularly long, had a lenticular section, hollowed at the forte, and were single or double-edged [24].

The widespread diffusion of this type of sword in the Veneto area, also evidenced by the large group of specimens kept in the armory of the Doge's Palace in Venice [24], has led to it being defined as the sword "alla veneta" (Venetian type) [32]. The development of the sword in the 15th century is not only related to a new way of fighting, exemplified by fencing treaties, but is, above all, related to the weapons production centers in the Venetian area. The higher quality of the iron, due to the indirect method, and the specialization of the craftsman that came with it (with new work profiles dedicated to an exclusive and specific task) also promoted the output of a better, and more complex, product. Overall, the arms production on the threshold of the Modern Age is the result of a complex combination of technological and social phenomena.

\section{Materials and Methods}

\subsection{The Swords}

The two swords of this study come from the "Luigi Marzoli" Arms Museum in Brescia. Due to their high degree of oxidation, these two swords could not be exposed in the museum; in this light, we were allowed to perform invasive diagnostic analyses. The first sword was defined as "G6", according to its serial number. The sword is not complete (Figure 1) and measures $187 \mathrm{~mm}$ in width and $430 \mathrm{~mm}$ in length; it weighs around $0.850 \mathrm{Kg}$ [18]. Collected samples of the G6 sword are listed in Table 1.

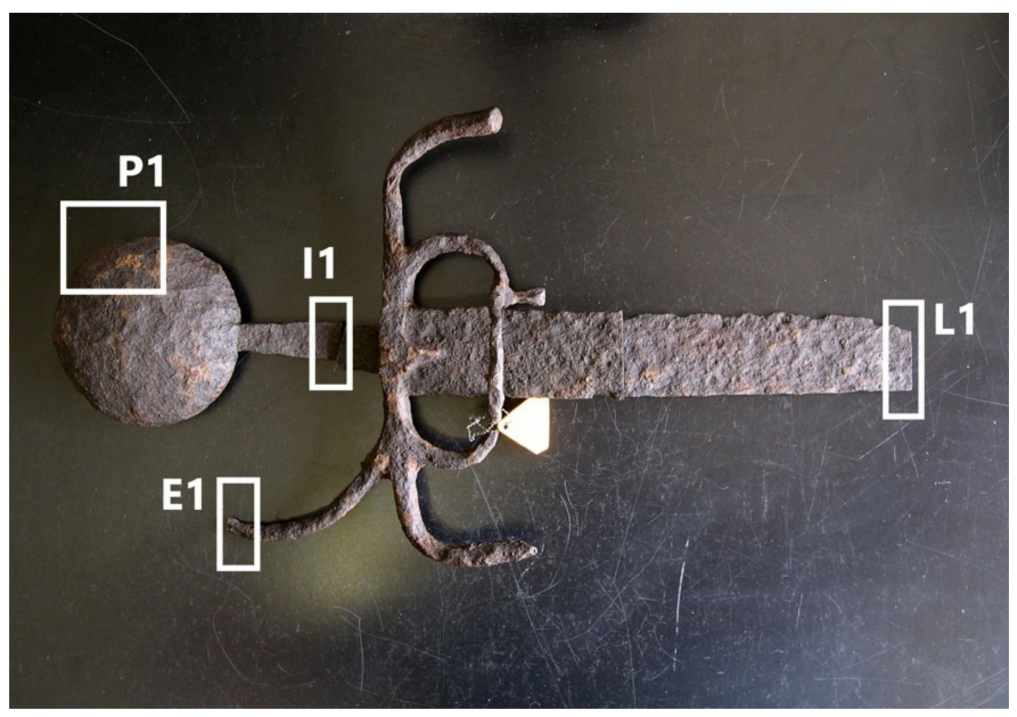

Figure 1. Sword G6 sites of sampling.

Table 1. Description of sword G6 samples.

\begin{tabular}{cc}
\hline Sample & Description \\
\hline P1 & fragment of the pommel \\
E1 & fragment of the knuckle-guard \\
I1 & fragment of the tang \\
L1 & fragment between forte and medio \\
\hline
\end{tabular}


It was found in the area of Belluno (near Brescia, ITALY) and it is presumed to be of Venetian-Lombardy manufacturing, dated between $1480-1490$ A.D. [29,32,33]. The pommel, disk-shaped, has a lenticular section. The hilt of the sword, which has probably an octagonal section, presents a curved quillon (the forward quillon sticks out), knuckle-guard, branches, and ring-guard, with cuspidate quillon block buttoned up the top of branches. This type of blade is usually subdivided into three sections called: (i) forte, close to the tang: (ii) medio, middle part of the blade; (iii) debole, near the edge (for further information about the components of the sword, the reader can refer to Supplementary Materials, Figure S1). The blade has only one edge and has a triangular section. Samples collected from sword G6 are listed in Table 1.

The second sword, with serial number "G8", is intact. The whole length measures $780 \mathrm{~mm}$ and it weighs around $1.100 \mathrm{Kg}$ (Figure 2). Its provenance is uncertain, even though some speculations can be made as some stylistic features resemble those from northern Italy swords and could be dated around 1480 [29,32]. The pommel is disc-shaped with a groove to hit the shank. The sword-hilt has a flat and curved quillon, from which branches arise and the blade has two edges and a central fuller. Collected samples of the G8 sword are listed in Table 2.

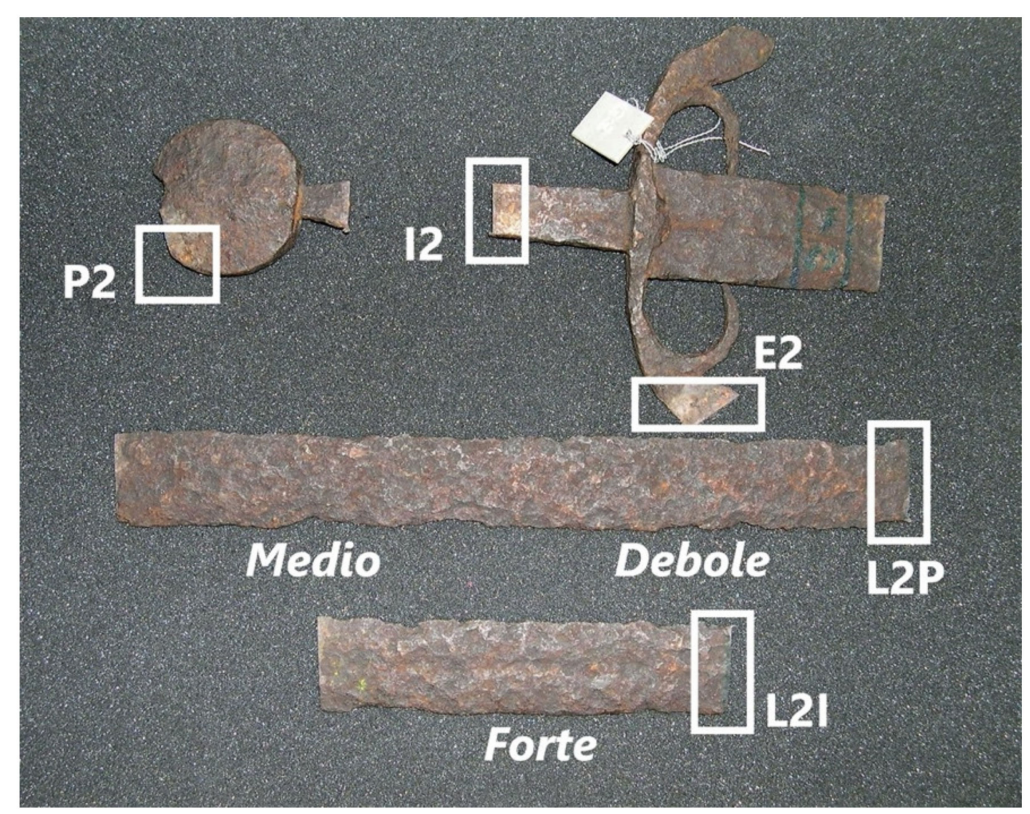

Figure 2. Sword G8 sites of sampling.

Table 2. Description of sword G8 samples.

\begin{tabular}{cc}
\hline Sample & Description \\
\hline P2 & fragment of the pommel \\
E2 & fragment of the quillon \\
I2 & fragment of the tang \\
L2I & fragment of forte \\
L2P & fragment of debole \\
\hline
\end{tabular}

\subsection{Analytical Protocols}

Prior to the instrumental analyses, the objects were visually inspected to detect evidence of shaping, soldering, and mechanically connected areas. Sampling fragments were selected to be representative and to preserve, to our best, the integrity of the objects. Later, the objects were carefully manipulated and subjected to instrumental analyses, to define the production techniques and the possible provenance. 


\subsubsection{Metallographic Examination}

Samples were mounted in epoxy resin, suitably polished with $\mathrm{SiC}$ emery paper from 400 to 1200 grit and with diamond paste up to $1 \mu \mathrm{m}$, according to the ASTM E3-95 standard adjusted to cultural heritage objects. Observations through Light Optical Microscopy were carried out after two different chemical etching: (i) Nital $1 \%\left(1 \%\right.$ of $\mathrm{HNO}_{3}$ in ethanol $v / v$ ) to reveal the presence of different phases and possible thermo-mechanical treatments; (ii) $\mathrm{FeCl}_{3}$ solution $(5 \mathrm{~g})$ in $\mathrm{HCl}(50 \mathrm{~mL})$ and ethanol $(200 \mathrm{~mL})$ to evidence compositional heterogeneities and grains orientation. To estimate the grain size of the samples, an image analysis software (Fiji-ImageJ, version 1.49b) was used on 200x LOM micrographs [34].

\subsubsection{SEM-EDS and EMPA-WDS Experiments}

A JEOL JSM-IT500 LV Scanning Electron Microscope (SEM), equipped with Backscattered (BSE) and Secondary Electrons (SE) detectors, was employed, at the Earth Sciences Department of the University of Milano (ESD-UniMI), with operating conditions: $20 \mathrm{kV}$ accelerating voltage, $65 \mu \mathrm{A}$ current beam. Quantitative/semi-quantitative chemical microanalysis through Energy Dispersive X-ray Spectroscopy (EDS) was carried out on the inclusions. Prior to EDS analysis, samples were carbon-coated. The ZAF correction was applied to the chemical data, as implemented in the JEOL suite of programs. This procedure allowed us to obtain reliable values for all elements with an atomic weight higher than sodium (i.e., $Z \geq 11$ ), while for lighter elements, like oxygen, the analysis was considered semi-quantitative. Fractions below $0.3 \mathrm{wt} . \%$ were also considered as semi-quantitative and were considered only when the identification peaks were clearly visible in the acquisition spectrum. Trace elements cannot be detected with SEM-EDS, as below the limit of detection (LOD) of the instrument. The reported compositions of the inclusions correspond to the average of at least three independent measurements on non-corroded areas. Additional chemical microanalyses were performed in wavelength-dispersive mode (EPMA-WDS), using a JEOL JXA-8200 microprobe, at the ESD-UniMI. The microprobe was operated as follows: accelerating voltage of $15 \mathrm{kV}$, beam current of $5 \mathrm{nA}$, beam diameter of $5 \mu \mathrm{m}$, and counting time of $30 \mathrm{~s}$ on the peaks and $10 \mathrm{~s}$ on the backgrounds. Correction for matrix effects was applied using the PhiRhoZ method, as implemented in the JEOL suite of programs. A series of natural and synthetic standards were used.

\subsubsection{Microhardness Measurements}

Microhardness measurements were performed with a microdurometer (UHL VMHT Report: ISO 6507) on 200x areas on at least 5 points per microstructure, using the Vickers method and the following parameters: applied load $500 \mathrm{~g}$; dwell time $15 \mathrm{~s}$.

\section{Results and Discussion}

\subsection{Swords Manufacturing: Microstructural Analysis}

By a visual observation of the samples collected from the two swords, it is possible to infer that the objects reproduce the period style (i.e., Venetian-Lombardy manufacturing, dated between 1480-1490 A.D.) (Figure 3) [32,33], as described in the Materials and Methods section. Interestingly, the pommel P1 $(80,5 \varnothing \times 18 \mathrm{~mm})$ is larger than P2 $(55 \varnothing \times 16 \mathrm{~mm})$ but hollow. 


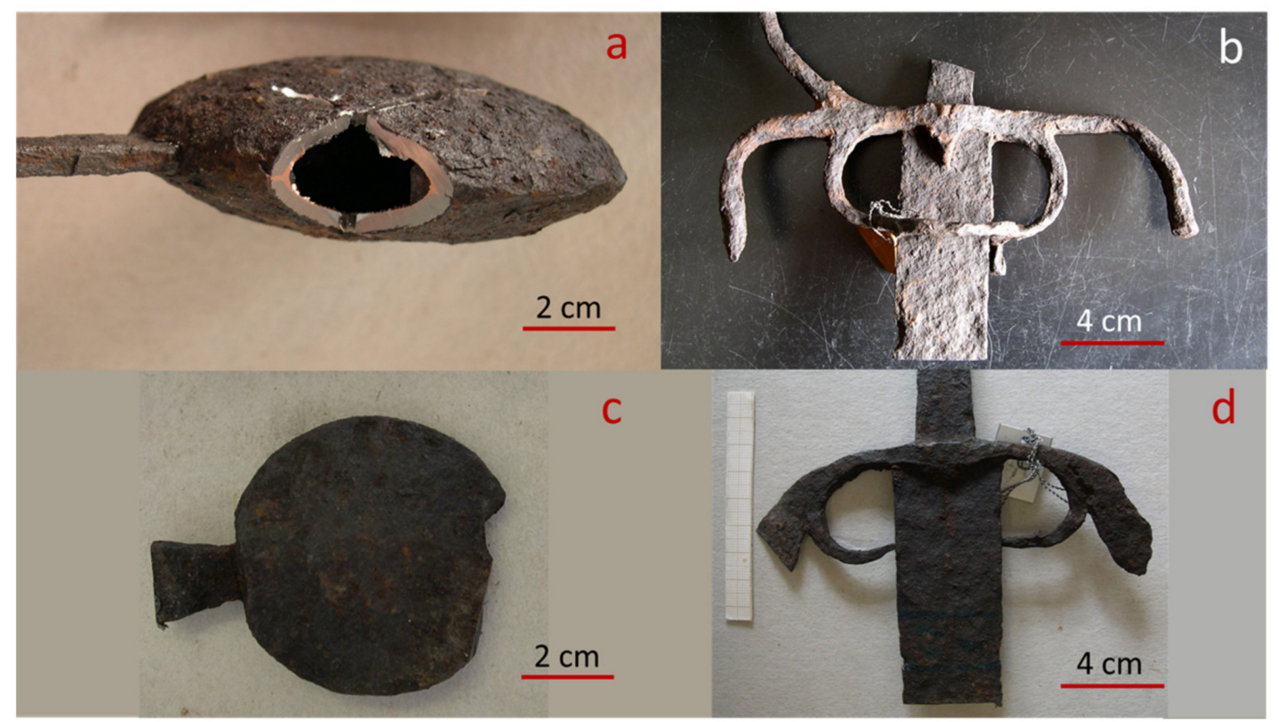

Figure 3. Comparison between the two pommels and the rest of the hilt. (a) G6 pommel; (b) G6 knuckle-guard; (c) G8 pommel; (d) G8 hilt. The G6 pommel is hollow and bigger than the G8 one. G6 hilt has the knuckle-guard, not present in the G8 hilt, but both hilts have curved quillons that were useful for stopping and diverting the downward blows.

The main function of this tool is balancing the whole sword, as it weighs the same as the rest of the weapon. This outcome is consistent with previous literature studies [32], considering the total length of the swords (G6's preserved length is $430 \mathrm{~mm}$ and G8's is $780 \mathrm{~mm}$ ). It also seems that, for P1, the two hemispheres are joined together (Figure 3a). Both hilts present curved quillons, useful for protecting against the downward blows; additionally, G6 has the knuckle-guard as further protection against enemies' blows [33] (Figure $3 \mathrm{~b}, \mathrm{~d}$ ). During the 13th century, the blacksmiths had begun to create ergonomic hilts in different models that go back to the Venetian sword. The G6 quillons shape is quite different from other models, and it could have anticipated the curved quillons present from the 14th century [33]. To our knowledge, no similar swords have ever been reported and described in the literature so far.

Microscopical observation of all samples revealed several microstructural heterogeneities (Figure 4), either among the samples or even in the same sample. Microstructural differences were more evident in the hilt and the blade, according to their function.
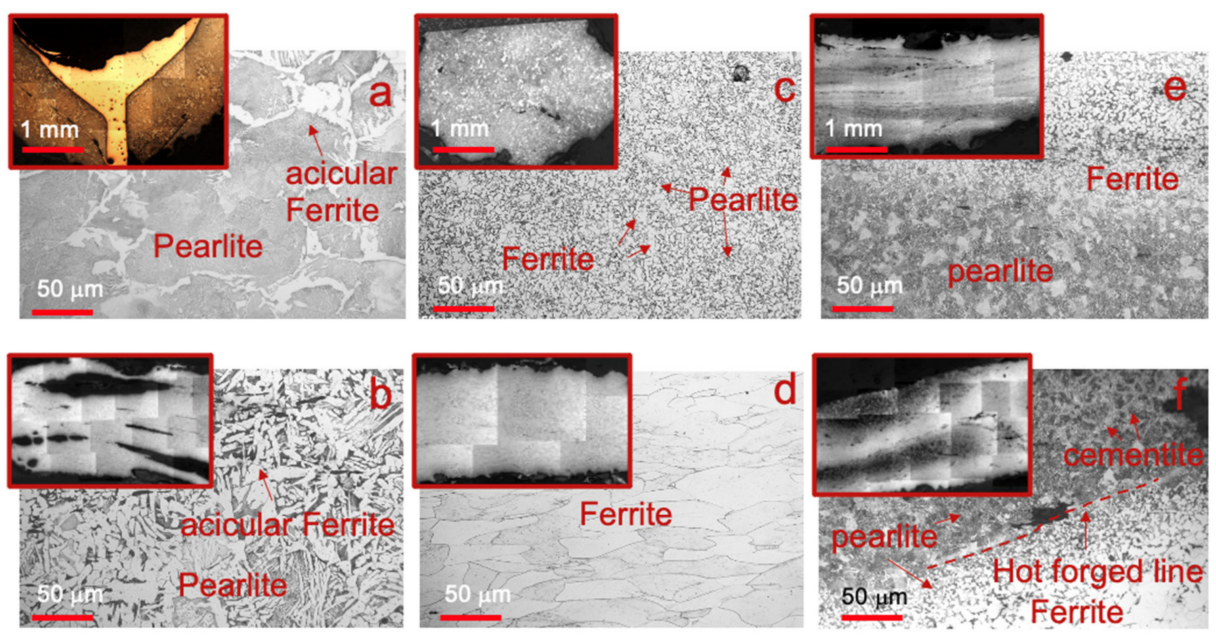

Figure 4. LOM micrographs and microstructural details: (a) the pommel of G6 or P1; (b) the pommel of G8 or P2; (c) the knuckle-guard or E1; (d) the quillon or E2; (e) the G6's tang or I1; (f) the G8's tang or I2. 
Both P1 and P2 (Figure 4a,b) showed predominantly pearlite and acicular (Widmanstätten like) ferrite with rare inclusions distributed on its surface, derived from heating above the austenitization temperature (A3 critical point) and cooling comparable to an air quenching, representing the typical microstructure of forged carbon steel [1]. Whereas P1 showed an almost pearlitic microstructure, $\mathrm{P} 2$ exhibited a fair distribution of pearlite and ferrite, with small areas of cementite [35]. Probably, both the G6 and the G8 sword's pommels were warmed up on blazing coals, hammered and air quenched. This kind of forge matches the pommel microstructure and explains the several oxidized areas. It was also possible to observe the application of a copper-based alloy to join the two hemispheres of the pommel P1 (Figure S2, Supplementary Materials, as later confirmed by the SEM-EDS analyses).

The two hilts' samples, knuckle-guard (E1) and quillon (E2), showed a microstructure with dominant ferrite and small areas of perlite at the grain boundaries (Figure 4c,d). The elongated ferrite grains in E2 testify to an isodirectional deformation, followed by annealing due to the absence of strain lines and mechanical twins. The sample E1 showed no forging layers, despite presenting two grain sizes (Table S1) and internal inclusions. This evidence seems to corroborate the hypothesis proposed by Matteis et al. [18] that the knuckle-guard was made of a single bar and later repaired. Also, the E2 microstructure, typical of a very low purified carbon steel, suggests the use of a single bar, which was later manufactured into a foil with the procedure used for the pommel.

Rapid quenching effects are only visible on the blade edges and not on the hilts (Figure 5). As an example, microhardness measurements conducted on specific areas of the tang of the two swords gave average values lower than 210 and 175 HV for G6 and G8, respectively. In addition, the tangs (I1 and I2) differ from the rest of the samples in terms of microstructure and abundance of inclusions. In I1, it is possible to observe (Figure 2e) two different phases: (i) pearlite and ferrite with diverse grain sizes (Table S1); (ii) pearlite and cementite. On the other hand, sample I2 (Figure 4f) showed a higher average grain size (Table S2) and a sequence of microstructures from the top to the bottom: (i) ferrite and pearlite; (ii) pearlite and cementite; (iii) pearlite and acicular ferrite; (iv) pearlite and cementite. Furthermore, hot-forged lines were observed for both samples.
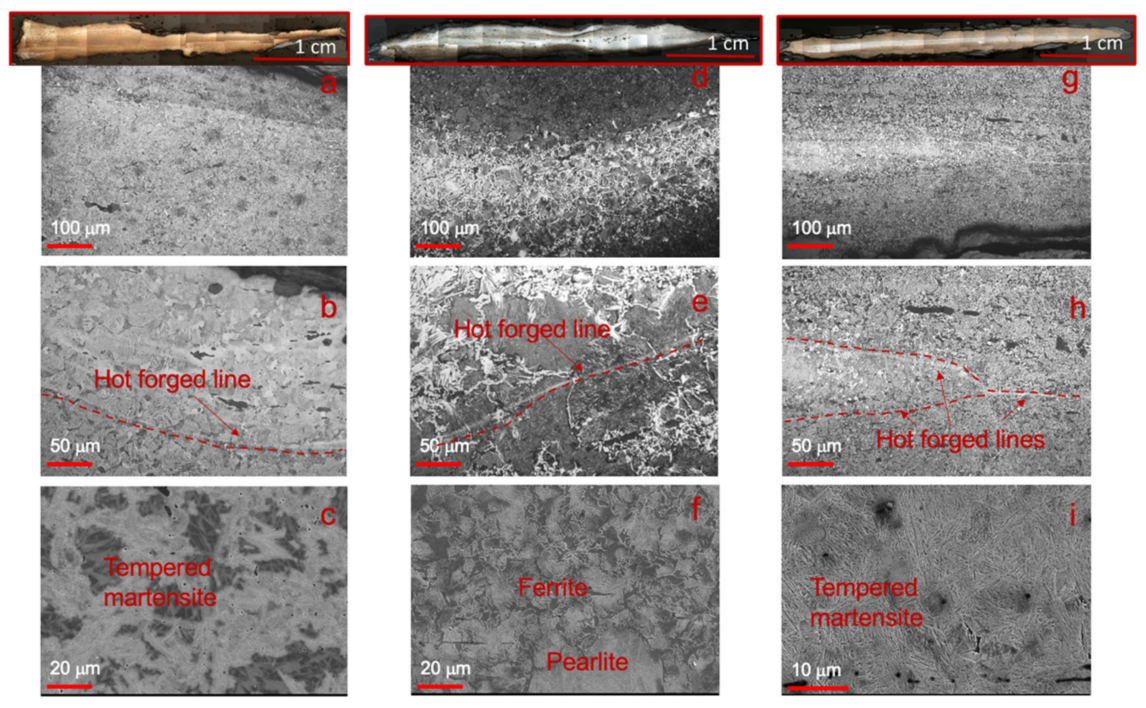

Figure 5. Micrographs and microstructural details. (a) tempered martensite in sample L1; (b) detail of (a), with hot-forged lines; (c) SEM detail of tempered martensite in L1; (d) ferrite and pearlite on the central part of L2I, corresponding to the hollow of the blade; (e) martensite, pearlite, and ferrite areas in L2I corresponding to water/oil and air quenching; (f) SEM detail of pearlite and ferrite; (g) hot-forged lines in sample L2P; (h) martensite, pearlite and ferrite areas in L2P corresponding to water/oil and air quenching; (i) SEM detail of tempered martensite with $\varepsilon$ carbides of L2P.

The G6's blade (sample L1), single-edged, has a heterogeneous appearance (Figure 5a-c). 
A sequence of microstructures characterizes the sample from the top surface to the bottom: (i) tempered martensite; (ii) ferrite and pearlite; (iii) tempered martensite; (iv) ferrite and pearlite; (v) tempered martensite. The interpretation of tempered martensite is given below: martensite being a solid solution, when present, it would appear as a mechanical mix of acicular grains. The size of such grains depends on the steel composition (e.g., carbon content) and the applied cooling rate due to the cooling medium (e.g., water, oil, etc.). After chemical etching, the martensite might appear dark at the optical microscope, while under the SEM observation it will show only the presence of acicular grains. Conversely, the tempered martensite corresponds to a matrix of body-centered tetragonal martensite, showing precipitated carbides ( $\varepsilon$ because in defect of $C$ if compared with the classical cementite) $[5,36,37]$. The SEM images (Figure $5 c$ ) showed that the original martensitic crystal has kept the same boundaries but results now hollow and containing tiny precipitates. If such a microstructure is further annealed, the martensite is transformed into ferrite (changing the grain boundaries and shape) with globular carbides (i.e., cementite) [36,37]. The sequence of microstructures observed could be related to several forging and folding steps above the $\mathrm{A} 3$ point, and two different cooling rates. The faster cooling rate is compatible with water or oil quenching [30,31], the slower could refer to an air quenching. The formation of tempered martensite is probably derived from further heating (probably below $250^{\circ} \mathrm{C}$ ) and followed by air cooling, which allows for the precipitation of $\varepsilon$ carbides (Figure 5c) [36]. According to the microstructural features and to the hardness measured by Vickers method, ranging between 480 and 580 HV0.5, it is, therefore, possible to infer that the observed microstructure might result from a temper annealing performed at intermediate temperatures [3,36]. Also, a difference was seen between the edge and the back edge (respectively on the right and left side of inset of 5a), with tempered martensite on the first, and pearlite and cementite on the latter. A hypothesis for the presence of cementite in the back-edge is as follows: during the forging, the blacksmith left one side of the blade on the blazing coals longer than the other side and applied an air cooling. Accordingly, on the backedge, quenched structures with an excess of carbon were produced, that formed grain boundary cementite. This hypothesis is also supported by the microhardness measurements (Table S3)

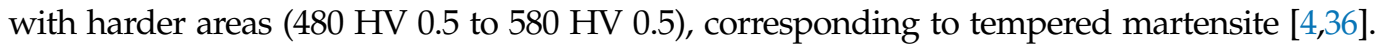
Hot-forged lines were also observed at the core of the blade (Figure 5a,b). They clearly define the folding procedure applied during hot-forging by the blacksmith.

The G8's blade samples (L2I and L2P), double-edged, are sampled near the grip and the edge, respectively, to observe how the microstructure differs between the forte and the debole (Figure $5 \mathrm{~d}-\mathrm{i}$ ). It appears that the alloy is made of iron with different carbon content along the transversal axis (Figure $5 \mathrm{~d}, \mathrm{~g}$ ). The hardness has irregular values, and it could be the result of different procedures: 530 HV 0.5 compared to 300 HV 0.5 [4]. Sample L2I is hollowed and has visible hot-forged lines (Figure 5e), which draw the forge folds and divide the microstructure from side to side into: (i) tempered martensite; (ii) pearlite and ferrite; (iii) tempered martensite; (iv) pearlite and acicular ferrite; (v) tempered martensite (Figure $5 \mathrm{f}$ ). The abundance of small inclusions near the hot-forged lines could be related to the supplementation of wet clays during the hot-forging that protects the material from oxidation and carburization [34]. In the sample L2P, the hot-forged lines are defined clearly by two kinds of microstructures (Figure 5h): (i) ferrite and pearlite at the center; (ii) tempered martensite on the edges (Figure 5i). The carburized layer, which is visible in L1, is not detected in L2P, thus confirming the use of a different procedure for the sword. The hardness profile of this sample is consistent with what was already observed for L1: in the core, the blade measures between 150 and $250 \mathrm{HV} 0.5$ and at the edges between 550 HV 0.5 and 600 HV 0.5 (Table S3) [4,37].

The SEM-EDS analyses provided information on the nature of the joint (Figures 6 and 7 and Tables 3 and 4). The main element detected is copper, with a low fraction of iron (average $3 \mathrm{wt} . \%$, spectrum 1 in Table 3). Figure 6 shows the difference in composition of the two parts (copper joint and iron), as reflected in a variation in greyscale, and the presence of solid-state interdiffusion (spectrum 1 and 2). 

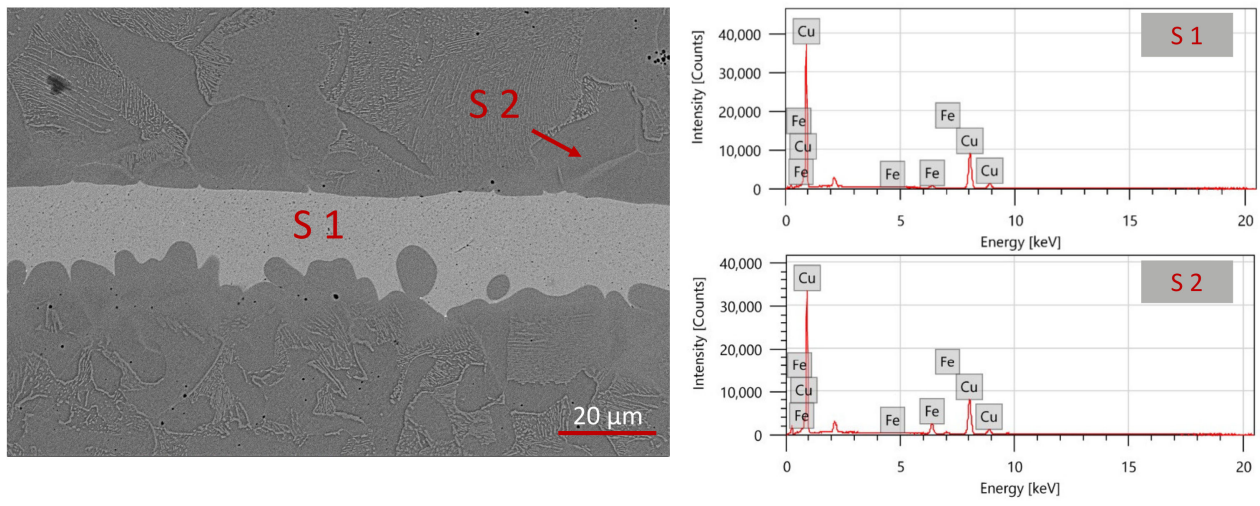

Figure 6. SEM-BSE micrograph of sample P1 copper joint.
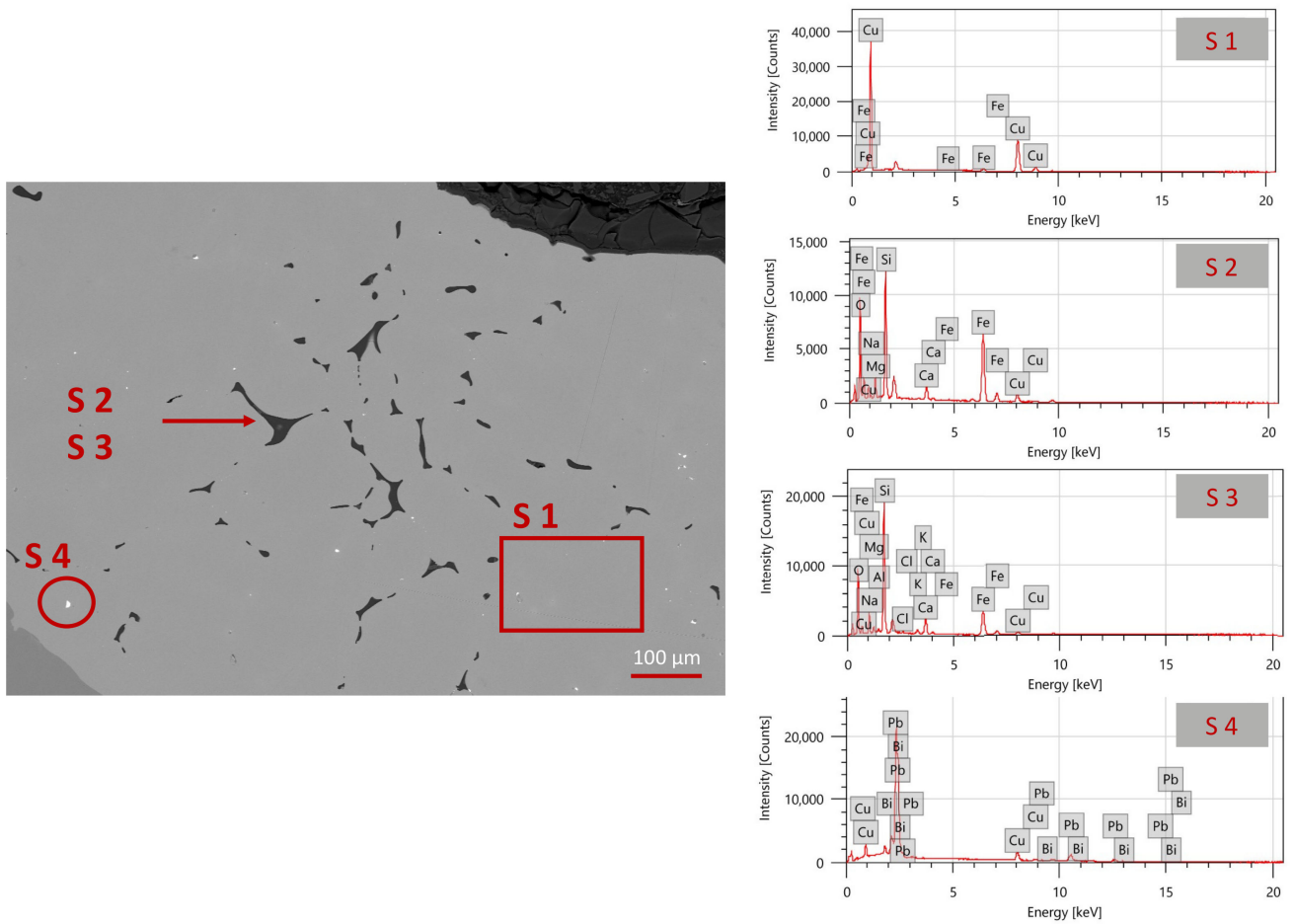

Figure 7. SEM-BSE micrograph of sample P1 copper joint.

Table 3. EDS microchemical analysis of the two points shown in Figure 6, in element wt\%.

\begin{tabular}{ccc}
\hline Spectrum & Fe & Cu \\
\hline 1 & 2.7 & 97.3 \\
2 & 13.1 & 86.9 \\
\hline
\end{tabular}

Table 4. EDS chemical microanalysis of the selected areas in Figure 7, in element wt\%.

\begin{tabular}{|c|c|c|c|c|c|c|c|c|c|c|c|c|}
\hline Spectrum & o & $\mathrm{Na}$ & $\mathrm{Mg}$ & $\mathrm{Al}$ & $\mathrm{Si}$ & $\mathrm{Cl}$ & K & $\mathrm{Ca}$ & $\mathrm{Fe}$ & $\mathrm{Cu}$ & $\mathrm{Pb}$ & $\mathrm{Bi}$ \\
\hline 1 & & & & & & & & & 3.1 & 96.9 & & \\
\hline 2 & 49.5 & 1.4 & 4.7 & 18.1 & & & & 2.0 & 20.6 & 3.6 & & \\
\hline 3 & 51.2 & 8.2 & 1.5 & 0.6 & 22.9 & 0.4 & 0.8 & 3.2 & 9.9 & 1.3 & & \\
\hline 4 & & & & & & & & & & 26.4 & 62.9 & 10.7 \\
\hline
\end{tabular}

The analysis of the microstructure (Figure 7) showed that the alloy appears homogeneous, with a few domains containing lead and bismuth (spectrum 4 in Table 4), usually associated with copper in $\mathrm{Cu}$-bearing mineral assemblage. In addition, dendritic grains are distinguished by the characteristic shape and silicate inclusions are observed at the 
grain boundaries (Figure 7). The hypothesized procedure is as follows: copper chips or grains were used to join the two hemispheres of the pommel using a clay shell that helped preserve the heat. The shell was supposedly warmed up above $1080^{\circ} \mathrm{C}$ (copper melting temperature) and air-cooled [38]. This allowed copper and iron to diffuse easily. The detected silicate-based inclusions (as displayed by the EDS spectra 02 and 03 in Figure 7 and Table 4), support this specific procedure. To our knowledge, such a material was never used on components of the swords coming from this period and the correct interpretation of these results would require further studies. However, it is not possible to exclude an interpretation either towards the innovation of the blacksmiths welding technique or a more recent reparation.

\subsection{Provenance of the Swords: Analysis of Inclusions}

The nature and distribution of inclusions can provide evidence on the provenance of raw materials and ores used for manufacturing. Both swords show the same results for the inclusions in terms of morphology and composition. Almost all of them appear elongated along the manufacturing direction and either uniform (usually with deep grey tones in BSE) or heterogeneous. Two differently shaped and sized inclusions were detected through SEM-EDS, as visible in Figure 8. Figure 8a displays the so-called bloomery or finery slags (according to the reducing process), which are bigger and homogeneously distributed on the samples. They generally give information about the provenance and the nature of iron ores [20].
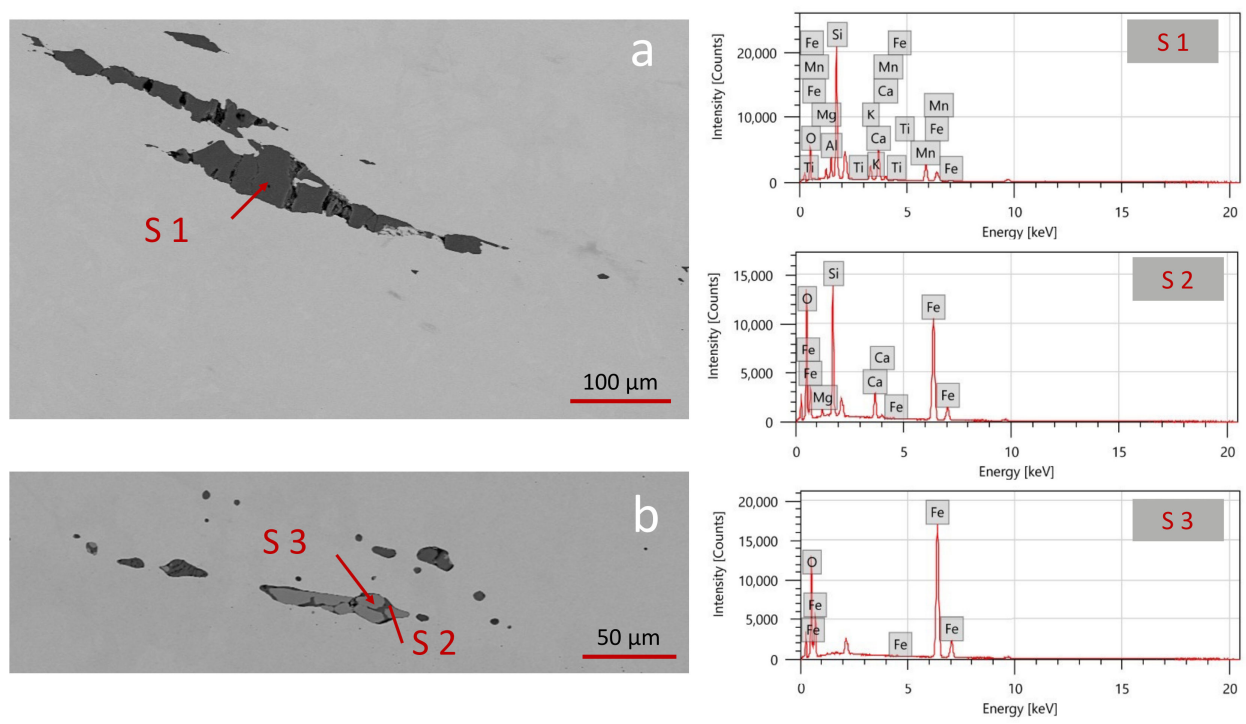

Figure 8. SEM-BSE micrograph and SEM-EDS spectra: (a) inclusions from sample L2I; (b) inclusions from sample L1.

Often, the inclusions contain small crystals (from 30 to $50 \mu \mathrm{m}$ ), with a polygonal or round shape. From the compositional analysis (Figure 8 a and Table 5), elements like Si, $\mathrm{Mg}, \mathrm{Al}, \mathrm{K}, \mathrm{Ca}, \mathrm{Ti}, \mathrm{Mn}$, and Fe were detected. This indicates that they are made of silicates, with an important fraction of $\mathrm{Mn}$, being this element knowingly a marker for bloomery slags [20]. It is known that $\mathrm{Mn}$ is preferably reduced during the smelting process and only a small fraction of $\mathrm{Mn}$ is re-oxidized in the finery process.

Table 5. EDS chemical microanalyses of the selected areas in Figure 8, in element at wto.

\begin{tabular}{cccccccccc}
\hline Spectrum & $\mathbf{O}$ & $\mathbf{M g}$ & $\mathbf{A l}$ & $\mathbf{S i}$ & $\mathbf{K}$ & $\mathbf{C a}$ & $\mathbf{T i}$ & $\mathbf{M n}$ & $\mathbf{F e}$ \\
\hline 1 & 45.7 & 2.5 & 4.2 & 25.5 & 3.2 & 7.3 & 0.2 & 7.2 & 4.2 \\
2 & 53.1 & 1.4 & & 15.3 & & 3.2 & & & 26.9 \\
3 & 46.2 & & & & & & & & 53.8 \\
\hline
\end{tabular}


Figure $8 \mathrm{~b}$ displays the smithing slags, derived from the hot-forging process, recognizable due to their morphology and location near the hot-forged lines observed through LOM [20]. They are smaller (around $100 \mu \mathrm{m}$ ) and elongated along the manufacturing direction. According to the literature, they are mainly composed of silicate minerals (clays) or ground bones [39]. As expected, analysis of the domains shown in Figure 8b confirms the presence of elements such as $\mathrm{Si}, \mathrm{Mg}, \mathrm{Ca}$, and $\mathrm{Fe}$. However, the compositional analysis suggests the presence of two distinct phases: the dark matrix in BSE is composed of silicates, the same composition of the inclusions in L1; the bright crystals are iron oxides. These outcomes confirm the aforementioned hypothesis of using wet clays to protect the iron from further oxidation. During this process, wustite or $\mathrm{FeO}$ (spectrum 3) is formed in lack of oxygen. A subsequent reaction with the silicate-based clay promoted the formation of fayalite $\mathrm{Fe}_{2} \mathrm{SiO}_{4}$ (spectrum 2).

To unambiguously distinguish bloomery from finery slags, Williams et al. suggested a protocol based on chemical quantitative analyses [20]. The compositions observed with the EDS analysis were used to set the WDS analysis, to obtain quantitative results in terms of chemical composition expressed as oxide $\mathrm{wt} \%$. According to Williams et al. [20], a direct process of production displays ratios of $\mathrm{K}_{2} \mathrm{O}: \mathrm{MgO}$ and / or $\mathrm{Al}_{2} \mathrm{O}_{3}: \mathrm{CaO}$ higher than those of $\mathrm{SiO}_{2}: \mathrm{Al}_{2} \mathrm{O}_{3}$. In addition, large quantities of $\mathrm{Mn}$ must be present in the silicates inclusions. Otherwise, iron is derived from an indirect process of production [20]. We then selected some relatively large inclusions, a reference one shown in Figure 9, to perform EMPA-WDS analyses and to apply the Williams et al. protocol. As shown by the spot analyses in Table 6, EMPA-WDS quantitative results confirm the heterogeneous nature of the inclusion. The chemical data pertaining to the ref. \#1 in Table 6 could be reasonably ascribed to an Mn-rich olivine (e.g., with the general formula $\left(\left(\mathrm{Fe}^{2+}, \mathrm{Mn}, \mathrm{Mg}\right)_{2}\left(\mathrm{SiO}_{4}\right)\right)$ or to an amorphous silicate with similar composition, whereas data pertaining to ref. \#2 point to glass, with a complex composition incompatible with the common rock-forming silicates. Unfortunately, the small dimensions of the inclusions do not permit a characterization based on X-ray diffraction methods, which would be decisive for the unambiguous identification of the Mn-rich olivine and of the glass.

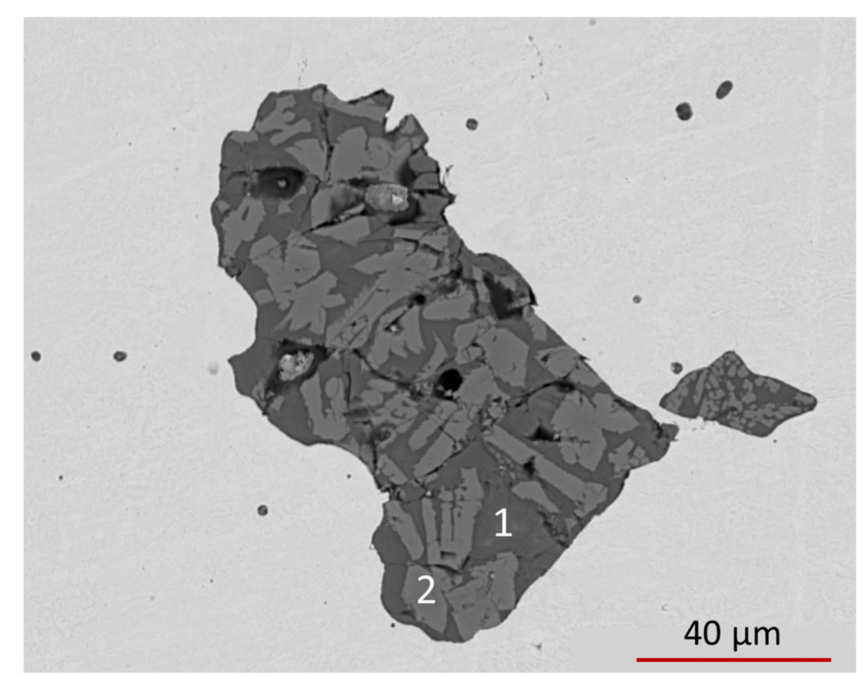

Figure 9. BSE image of an inclusion in sample I2. \#1 and \#2 correspond to the two WDS point-analyses of Table 6.

Table 6. EMPA-WDS analyses of sample I2, G8 sword: composition of a bloomery slag (in wt \%) from spot analyses of Figure 9 (LOQ $0.01 \mathrm{wt} \%$ ).

\begin{tabular}{ccccccccccccc}
\hline Spectrum & $\mathrm{Na}_{2} \mathrm{O}$ & $\mathrm{SO}_{3}$ & $\mathrm{MnO}$ & $\mathrm{K}_{\mathbf{2}} \mathrm{O}$ & $\mathrm{MgO}$ & $\mathrm{SiO}_{2}$ & $\mathrm{TiO}_{2}$ & $\mathrm{FeO}$ & $\mathrm{CaO}$ & $\mathrm{Al}_{2} \mathrm{O}_{3}$ & $\mathrm{Cr}_{2} \mathrm{O}_{4}$ & $\mathrm{NiO}$ \\
\hline 1 & 0.02 & 0.04 & 19.29 & 0.04 & 6.96 & 31.65 & 0.06 & 39.97 & 3.99 & 0.06 & 0.01 & $<\mathrm{LOQ}$ \\
2 & 0.14 & 0.66 & 4.87 & 6.05 & 0.32 & 37.52 & 0.69 & 23.7 & 13.65 & 8.85 & 0.01 & 0.08 \\
\hline
\end{tabular}


Applying the Williams et al. protocol, results are described in Table 7. For some parts of the blade, the $\mathrm{SiO}_{2}: \mathrm{Al}_{2} \mathrm{O}_{3}$ ratio is higher than that of $\mathrm{K}_{2} \mathrm{O}: \mathrm{MgO}$ (blade G6, pommel P1, knuckle guard E1, and quillon E2) and for other samples, the value is lower (pommel P2 and blade G8).

Table 7. $\mathrm{SiO}_{2}: \mathrm{Al}_{2} \mathrm{O}_{3}$ and $\mathrm{K}_{2} \mathrm{O}: \mathrm{MgO}$ ratio elaborated from the analyses via SEM-EDS and EMPA-WDS on the samples according to the Williams et al. protocol [24]. * = only the tangs were displayed as representative of the entire blade.

\begin{tabular}{ccc}
\hline Spectrum & $\mathrm{SiO}_{2}: \mathrm{Al}_{2} \mathrm{O}_{3}$ & $\mathrm{~K}_{2} \mathrm{O}: \mathrm{MgO}$ \\
\hline & $\mathrm{G6}$ & \\
$\mathrm{P} 1$ & $4.5 \pm 0.1$ & $2.1 \pm 0.1$ \\
$\mathrm{E} 1$ & $4.4 \pm 0.1$ & $2.0 \pm 0.1$ \\
$\mathrm{I} 1{ }^{*}$ & $5.4 \pm 0.8$ & $2.1 \pm 0.6$ \\
& $\mathrm{G} 8$ & \\
$\mathrm{P} 2$ & $2.6 \pm 0.3$ & $4.8 \pm 0.2$ \\
$\mathrm{E} 2$ & $8.0 \pm 2.0$ & $0.7 \pm 0.6$ \\
$\mathrm{I}{ }^{*}$ & $4.0 \pm 1.8$ & $19.0 \pm 8.4$ \\
\hline
\end{tabular}

Historically, both reduction processes were common practices in the 14th-17th centuries [28] and according to the outcomes obtained, the process applied for the reduction of the swords was both direct (G8) and indirect (G6). In addition, for the sword G8, the $\mathrm{SiO}_{2}: \mathrm{Al}_{2} \mathrm{O}_{3}$ and $\mathrm{K}_{2} \mathrm{O}: \mathrm{MgO}$ ratio values seem at first contradictory considering the different components. However, these outcomes are plausible if we consider that a direct process of production was applied for the blades and an indirect one for the hilt. Consequently, we could only consider a possible replacement of the hilt according to the changing fashion of the time [24].

To gather information on the iron ores, the composition of the inclusions was correlated to the minerals of the ores exploited to produce iron from the 13th century and coming from the Venetian area [24]. The most important iron-bearing mineral of the Brescia and Bergamo territories, probably exploited since the 6th-7th century (Lombard times), is represented by siderite occurring at the mines of Val Trompia and Val Camonica (near Brescia), and Val di Scalve-Val Seriana (near Bergamo). Siderite is an iron carbonate $\left(\mathrm{FeCO}_{3}\right)$, which contains up to $48 \mathrm{wt} \%$ of Fe. These mines consist of layers of (mainly Triassic) metasomatic carbonate rocks (limestones, dolostones, and mudstone), with different siderite content. The richest levels contain even up to ca. $75 \mathrm{wt} \%$ in siderite. A common feature of the siderite from these ores is the high fraction of Mn. A similar geological scenario occurs even in the Dolomites area, for example in the Fursil mine, in which Mn-rich siderite occurs [31,40,41]. Other minerals of industrial interest occur with siderite, which has been exploited over time: in Val Trompia, for example, where fluorite $\left(\mathrm{CaF}_{2}\right)$, barite $\left(\mathrm{BaSO}_{4}\right)$, silver-bearing galena $(\mathrm{PbS})$, chalcopyrite $\left(\mathrm{CuFeS}_{2}\right)$, tetrahedrite $\left((\mathrm{Cu}, \mathrm{Fe}){ }_{12} \mathrm{Sb}_{4} \mathrm{~S}_{13}\right)$, and sphalerite $(\mathrm{ZnS})$ occur. Therefore, even copper is a metal occurring in the minerals available and exploitable at the Val Trompia mines, but not at all the other mines of the Brescia and Bergamo territory. The co-presence of $\mathrm{Pb}$ (along with $\mathrm{Bi}$ or S) observed in some of the chemical analyses of this study is compatible with the mineralogical assemblage of the ore.

The metals used to produce the swords in this study are available in the Brescia and Bergamo territories. The chemical compositions of the previously described inclusions cannot be used as markers for unambiguous identification of the parent ores: $\mathrm{Si}, \mathrm{Mg}, \mathrm{Al}$, $\mathrm{K}, \mathrm{Ca}, \mathrm{Ti}, \mathrm{Mn}$, and $\mathrm{Fe}$, which are compatible with the mineralogical assemblages of the metasomatic carbonate rocks (limestones, dolostones, and mudstone), found rich of siderite, from the different mines. The multi-elemental composition of the (likely amorphous) inclusions makes it difficult to reconstruct the melting temperature. 


\section{Conclusions}

Two Venetian type swords coming from the "Luigi Marzoli" Arms Museum in Brescia were analyzed in this study. The microstructural analyses suggest that only the blade edges were water or oil quenched, while the hilt components were probably air quenched. Concerning the different parts of the blades, it was observed for both the swords that the forte edges were subjected to different thermal treatments, while the debole shows the same out-of-equilibrium microstructure on the edges. It suggests that tempering was an essential thermal treatment for this part of the blade. The assembly procedure of the G6 pommel was unique and, to our knowledge, never found for this type of sword. The two hemispheres were joined together with a copper alloy to improve their cohesion.

The analyses of inclusions suggest a direct process of ironmaking for the blade and the pommel of G8 and an indirect one for the whole sword G6. Also, the same process (indirect), but with some uncertainty, can be assumed for the quillon of the G8, suggesting a possible replacement. The composition of bloomery slag is consistent with the mineral assemblage of the siderite-rich carbonate rocks (limestones, dolostones, and mudstone) of the Brescia and Bergamo territories. The Val Trompia ore, which was one of the most exploited of the territory (containing iron and even copper-bearing minerals) is compatible with the chemical composition of the metal alloys of the swords and of the non-metallic inclusions. This suggests the coexistence of both processes during this period and in this geographical area. There are two historical pieces of evidence that can support this hypothesis: i) the presence of "canecchio" furnace in Venetian areas during the diffusion of the ergonomic hilts; ii) the documented use of finery iron for making armors, because of its good mechanical properties. However, further analyses are needed to unambiguously determine the production process of the single components of the swords, considering also that many of them were replaced according to the fashion of the period.

Supplementary Materials: The following are available online at https:/ / www.mdpi.com/article/ 10.3390/heritage4030069/s1, Figure S1: Sections of the sword-hilt, Figure S2: Hot forged lines in sample P2, Figure S3: Dendritic structure of copper welding the two hemispheres of the pommel P1, Table S1: Grain size of the blade G6 estimated on 200x LOM micrographs according to the different microstructure observed, Table S2: Grain size of the blade G8 estimated on 200x LOM micrographs according to the different microstructure observed, Table S3: Microhardness profiles of samples L1 and L2I.

Author Contributions: Conceptualization, C.M. and S.P.T.; methodology, C.M. and G.G.; formal analysis, C.M. and G.G.; investigation, C.M., GG., P.P. and G.D.G.; resources, C.M. and P.D.M.; data curation, C.M. and S.P.T.; writing — original draft preparation, C.M., G.G. and P.D.M.; writing-review and editing, G.D.G., P.P. and S.P.T.; visualization, C.M.; supervision, S.P.T. All authors have read and agreed to the published version of the manuscript.

Funding: This research received no external funding.

Institutional Review Board Statement: Not applicable.

Informed Consent Statement: Not applicable.

Data Availability Statement: The data presented in this study are available on request from the corresponding author.

Acknowledgments: The authors would like to thank the "Luigi Marzoli" Arms Museum in Brescia in the person of Marco Merlo for giving us the opportunity to analyze the objects from their renaissance collection. A special thanks to: Ruben Beltrami for their support in the analytical interpretation of the results; Stefania Crespi and Andrea Resplendente from Department of Earth Sciences-Univ. Milano, for the assistance during the SEM-EDS and EMPA-WDS measurements, respectively.

Conflicts of Interest: The authors declare no conflict of interest. 


\section{References}

1. Fulford, M.; Sim, D.; Doig, A.; Painter, J. In defence of Rome: A metallographic investigation of Roman ferrous armour from Northern Britain. J. Archaeol. Sci. 2005, 32, 241-250. [CrossRef]

2. Sherby, O.D.; Wadsworth, J. Ancient blacksmiths, the Iron Age, Damascus steels, and modern metallurgy. J. Mater. Proc. Technol. 2011, 117, 347-353. [CrossRef]

3. Yaso, M.; Takaiwa, T.; Minagi, Y.; Kanaizumi, T.; Kubota, K.; Hayashi, T.; Morito, S.; Ohba, T. Study of Japanese sword from a viewpoint of steel strength. J. Alloys Compd. 2013, 577S, S690-S694. [CrossRef]

4. Fajfar, P.; Medved, J.; Klančnik, G.; Lazar, T.; Nečemer, M.; Mrvar, P. Characterization of a Messer-The late-Medieval single-edged sword of Central Europe. Mater. Character 2013, 86, 232-241. [CrossRef]

5. Edge, D.; Williams, A. Some Early Medieval Swords in the Wallace Collection and Elsewhere. Gladius 2003, XXIII, 191-210. [CrossRef]

6. Wadsworth, J. Archeometallurgy related to swords. Mater. Character 2015, 99, 1-7. [CrossRef]

7. Williams, A. A Metallurgical Study of Some Viking Swords. Gladius, 2009; XXIX, 121-184, Estudios sobre armas antiguas, arte militar y vida cultural en oriente y occidente.

8. Jones, P.N. The Metallography and Relative Effectiveness of Arrowheads and Armor During the Middle Ages. Mater. Character 1992, 29, 111-117. [CrossRef]

9. Ghiara, G.; Piccardo, P.; Campodonico, S.; Carnasciali, M.M. Microstructural features in corroded Celtic Iron Age sword blades. JOM 2014, 66, 793-801. [CrossRef]

10. Worley, J. The Chemistry of Swords: Using Analytical Chemistry Techniques to Investigate Medieval Swords. Arms Armour 2015, 12, 53-66. [CrossRef]

11. Dumont, L.; Dupuy, V.; Nicolas, T.; Pelé-Meziani, C.; De Mulder, G. The protohistoric sword from Le Gué-de-Velluire (Vendée, France): A pasticcio's history unveiled by archaeometrical research. J. Archaeol. Sci. Rep. 2020, 34A, 102645.

12. Kino, K.; Ayukawa, N.; Kiyanagi, Y.; Uchida, T.; Uno, S.; Grazzi, F.; Scherillo, A. Analysis of crystallographic structure of a Japanese sword by the pulsed neutron transmission method. Phys. Proced 2013, 43, 360-364. [CrossRef]

13. Grazzi, F.; Cantini, F.; Salvemini, F.; Scherillo, A.; Schillinger, B.; Kaestner, A.; Edge, D.; Williams, A. The investigation of Indian and central Asian swords and through neutron methods. J. Archaeol. Sci. Rep. 2018, 20, 834-842. [CrossRef]

14. Salvemini, F.; Williams, A.; Edge, D.; Schillinger, B.; Cantini, F.; Grazzi, F. On the use of neutron imaging methods to identify microstructural features in ancient Indian swords and armour. Microchem. J. 2020, 159, 105397. [CrossRef]

15. Fedrigo, A.; Grazzi, F.; Williams, A.R.; Panzner, T.; Lefmann, K.; Lindelof, P.E.; Jørgensen, L.; Pentz, P.; Scherillo, A.; Porcher, F.; et al. Extraction of archaeological information from metallic artefacts-A neutron diffraction study on Viking swords. JAS Rep. 2017, 12, 425-436. [CrossRef]

16. Harjo, S.; Kawasaki, T.; Grazzi, F.; Shinohara, T.; Tanaka, M. Neutron diffraction study on full-shape Japanese sword. Materialia 2019, 7, 100377. [CrossRef]

17. Tonelli, G.; Faccoli, M.; Gotti, R.; Roberti, R.; Cornacchia, G. Historical and Metallurgical Characterization of a "Falchion" Sword Manufactured in Caino (Brescia, Italy) in the Early 17th Century A.D. JOM 2016, 68, 2233-2249. [CrossRef]

18. Matteis, P.; Scavino, G.; Merlo, M. Metallurgical analysis of two renaissance swords. In Proceedings of the Congress Acts "Il Museo Marzoli e le Armi Lombarde", Brescia, Italy, 15-17 November 2018.

19. Cornacchia, G.; Faccoli, M.; Roberti, R. Metallurgical Investigation of a Steel Miner's Chisel from Ponte Val Gabbia III Site. JOM 2015, 67. [CrossRef]

20. Williams, A. The Knight and the Blast Furnace, a History of the Metallurgy of Armour in the Middle Age and the Early Modern Period; Brill Leiden: Boston, MA, USA, 2003; pp. 877-892.

21. Williams, A. The Sword and the Crucible, A History of the Metallurgy of European Swords up to the 16th Century; Brill Leiden: Boston, MA, USA, 2012; pp. 49-61.

22. Brocchi, G.B. Trattato Mineralogico e Chimico Sulle Miniere di Ferro del Dipartimento del Mella con L'esposizione della Costituzione Fisica delle Montagne Metallifere della Val Trompia; Forgotten Books: Brescia, Italy, 2018; Volume I, pp. 57-124.

23. Braunstein, P. (Ed.) La Siderurgie Alpine en Italie (XIIe-XVIIe Siècle); École Française de Rome: Roma, Italy, 2001.

24. Boccia, L.G. Armi Bianche Italiane; (Data Sheet 156); Bramante Editrice: Milano, Italy, 1975; pp. 9-29.

25. Cavalli, M. Relazione del 1554. In Relazioni dei Rettori Veneti in Terraferma. Vol. XI: Podestaria e Capitanato di Brescia, Varese; Tagliaferri, A., Dott., A., Eds.; Giuffrè Editore: Bergamo, Italy, 1978; pp. 47-52.

26. Correr, P. Relazione del 1562. In Relazioni dei RETTORI Veneti in Terraferma. Vol. XI: Podestaria e Capitanato di Brescia, Varese, Tagliaferri, A., Dott. A., Eds.; Giuffrè Editore: Bergamo, Italy, 1978; pp. 59-86.

27. Vergani, R. Tra Vescovi e Forni: La Siderurgia Bellunese nei Secoli XII-XVI. In Terra e Storia. Rivista di Storia e Cultura; Anno, V.N.9; Cierre Edizioni: Roma, Italy, 2016; pp. 9-56.

28. Simoni, C. Dai forni alla bresciana ai forni elettrici. In L'industria del Ferro e Dell'acciaio nel Bresciano. Il caso della Val Camonica; Facchini, C., Simoni, C., Predali, R., Eds.; FdP: Brescia, Italy, 2011; pp. 27-29.

29. Tranchini, E.; Foti, F. Le Antiche Fabbriche di Armi Bianche a Ceneda e a Serravalle; T.E.T: Treviso, Italy, 1983.

30. Rossi, F. Armi e Armaioli Bresciani del 400; Tipo-Lito Fratelli Geroldi: Brescia, Italy, 1972.

31. Vello, M.; Tonin, F. Spade e Spadai Bellunesi Negli Anni 1500-1600; Istituto Bellunese Ricerche Storiche: Belluno, Italy, 2018. 
32. Marchesi, G. Le Miniere di ferro della Valle Trompia. Una lunga storia di fatica ed ingegno. In Proceedings of the Congress acts "Il Museo Marzoli e le armi lombarde", Brescia, Italy, 15-17 November 2018.

33. De Vita, C. Dizionari Terminologici. Armi Bianche dal Medioevo all'Età Moderna; Centro Di: Firenze, Italy, 1983.

34. Schindelin, J.; Arganda-Carreras, I.; Frise, E.; Kaynig, V.; Longair, M.; Pietzsch, T.; Preibisch, S.; Rueden, C.; Saalfeld, S.; Schmid, B.; et al. An Open-Source Platform for Biological-Image Analysis. Nat. Methods 2012, 9, 676-682. [CrossRef] [PubMed]

35. Grazzi, F.; Barzagli, E.; Scherillo, A.; De Francesco, A.; Williams, A.; Edge, D.; Zoppi, M. Determination of the manufacturing methods of Indian swords through neutron diffraction. Microchem. J. 2016, 125, 273-278. [CrossRef]

36. Cahn, R.W.; Haasen, P. Physical Metallurgy, 4th ed.; North Holland: Cambridge, UK, 1996.

37. Smallman, E.R.; Ngan, A.H.W. Modern Physical Metallurgy, 8th ed.; Butterworth-Heinemann: London, UK, 2014.

38. Maryon, H Metal Working in the Ancient World. Am. J. Archaeol. 1949, 53, 93-125. [CrossRef]

39. Serneels, V.; Perret, S. Quantification of smithing activities based on the investigation of slag and other material remains. In Proceedings of the Archeometallurgy in Europe Proceedings, Milano, Italy, 24-26 September 2003; Volume II, pp. $469-478$.

40. Omenetto, P. Le Risorse Minerarie Della Regione di Belluno. In Proceedings of the Atti della Giornata di Studi Geominerari, Arti Grafiche Saturnia, Trento, Italy, 7 October 1967; pp. 31-42.

41. Neri, C.; Stefani, M. Sintesi cronostratigrafica e sequenziale dell'evoluzione permiana superiore e triassica delle Dolomiti. Mem. Della Soc. Geol. Ital. 1998, 53, 417-463. 